\title{
DYNAMIC INSTRUMENTATION OF THE THORACIC SPINE
}

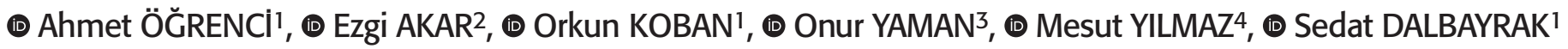 \\ ${ }^{1}$ Okan University Faculty of Medicine, Department of Neurosurgery, Istanbul, Turkey \\ ${ }^{2}$ Haydarpaşa Numune Training and Research Hospital, Clinic of Neurosurgery, İstanbul, Turkey \\ ${ }^{3}$ Memorial Bahçelievler Hospital, Clinic of Neurosurgery, İstanbul, Turkey \\ ${ }^{4}$ Neurospinal Academia, Department of Neurosurgery, İstanbul, Turkey
}

\begin{abstract}
The aim of this report was to present a new surgical alternative for pathologies affecting the thoracic spine, and to also share our experience of treating such cases using dynamic systems. Two patients exhibiting thoracic spine pathologies (traumatic disc herniation and thoracic stenosis) that did not necessarily require surgery using rigid systems were selected for stabilization using the dynamic system. The patients exhibited a decrease in postoperative visual analog scale scores, and the follow-up period remained uneventful. The results of this report suggest that dynamic systems can be used as an alternative to rigid systems for treatment of thoracic spine pathologies.
\end{abstract}

Keywords: Dynamic instrumentation, peek rod, thoracic

\section{INTRODUCTION}

Although there is considerable scientific evidence on the surgical treatment of thoracic spine pathologies available, the majority of studies carried out to date tend to focus on the use of rigid systems. The efficacy of these systems are wellestablished; however, the treatments does not require with the rigid systems for the patients are not clear ${ }^{[1,2)}$. Various industrial materials and systems for surgical treatment of the lumbar spine have been developed and, despite lack of a common consensus, there is a general tendency towards certain treatment options (dynamic, rigid, or hybrid systems) for specific pathologies $(2,3)$. All segments of the human spine contribute to spinal alignment and allow movement in motion. The occurrence of various pathologies affecting range of motion in the lumbar region of the spine led to the development of dynamic systems specifically designed for this region which, in turn, highlighted the need for similar developments in treatment options for the thoracic spine $e^{(4)}$. The thoracic vertebrae are not stationary and exhibit considerable stability, despite having inferior range of motion compared to other regions. Pathologies such as disc herniation, traumatic fractures, osteoporotic compression fractures, and thoracic stenosis affecting these regions typically result in a degradation of stability.
This case report presents two patients treated for pathologies affecting the thoracic spine using dynamic instrumentation.

\section{CASE REPORT}

Retrospective evaluation of two patients diagnosed with multiple thoracic disc herniation after trauma and myelomalacia due to thoracic stenosis and treated using thoracic dynamic systems [with straight PolyEtherEtherKetone (PEEK) rod] at our clinic between 2014 and 2015 was carried out. The median age of the patients was 42.5 (31-54) years, and the mean follow-up period was 27 (20-34) months.

Posterior decompression and stabilization of the spine using T1-6 titanium screws and straight PEEK rods was carried out to treat the patient diagnosed with multiple disc herniations after trauma. The second patient exhibiting T10-11 stenosis with myelomalacia was treated using T10-11 segmental stabilization after decompression (total laminectomy + bilateral partial medial facetectomy) (Figure 1a-d).

Radiological examination of the patients was carried out at the last follow-up appointment although, and the visual analog scale (VAS) scores of the patients in the preoperative ( $1^{\text {st }}$ month) and postoperative (last examination) periods were recorded and checked for improvement. Both patients exhibited improvement in VAS scores and a decrease in pain scores in

Address for Correspondence: Ezgi Akar, Haydarpaşa Numune Training and Research Hospital, Clinic of Neurosurgery, İstanbul, Turkey E-mail: ezgiaycicek@gmail.com Received: 04.06.2020 Accepted: 25.10.2020

ORCID ID: orcid.org/0000-0002-8582-2948 

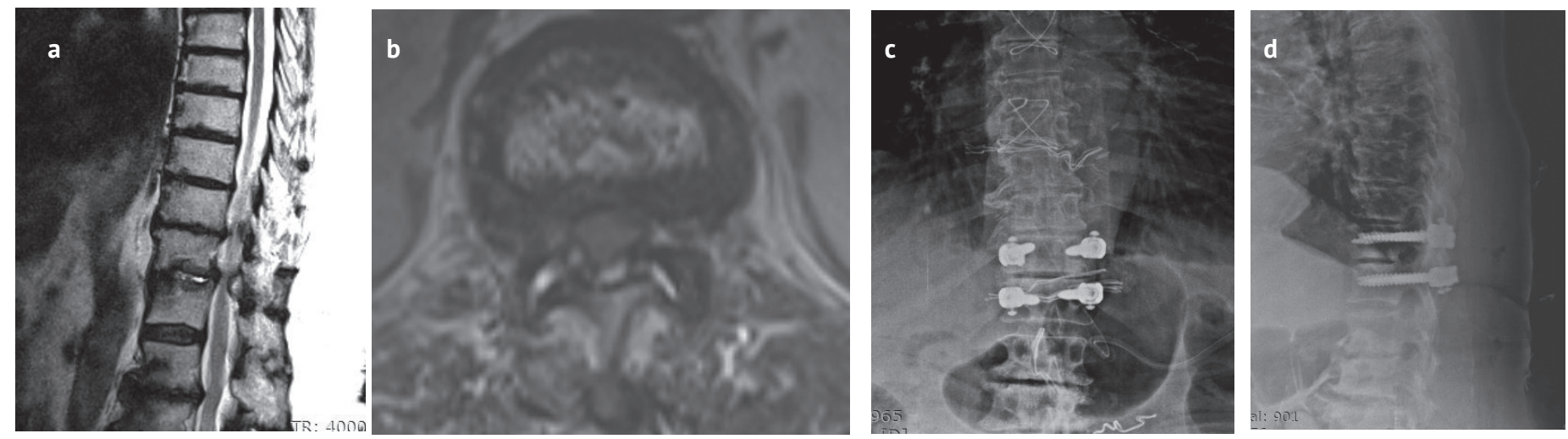

Figure 1. A 54-year old female patient exhibiting gait disturbance presented at our clinic. Radiological examination showed myelomalacia and thoracic spine stenosis at the T10-11 levels $(\mathbf{a}, \mathbf{b})$. Decompression with laminectomy, partial medial fasetectomies, and dynamic stabilization using PEEK rods was carried out (c, d).

PEEK: Poly Ether Ether Ketone

the $1^{\text {st }}$ month postoperatively (Table 1), although statistical evaluation could not be carried out due to the small sample size. The last follow-up appointment showed no increase in pain scores, and radiological examination confirmed no problems with the stabilization systems.

\section{DISCUSSION}

Rapid developments in diagnostic methods such as computerized tomography and magnetic resonance imaging have led to increased detection of pathologies affecting the thoracic region ${ }^{(1)}$. A recent study in Japan found that the rate of surgical interventions for pathologies affecting the thoracic region, such as thoracic masses, discopathies, and infectious pathologies, were unexpectedly high at $6 \%^{(1-3)}$. However, despite an increase in the frequency of interventions in this region, instrumentation has always typically been based on rigid systems and there is limited evidence available on the use of dynamic systems in the thoracic region. This can be attributed to the fact that the thoracic region has always been perceived as being rigid, resulting in limited biomechanical development of dynamic systems for this region.

A large number of studies have examined the range of motion in the cervical and lumbar regions ${ }^{(4-7)}$, and comparison of the range of motion produced by rigid and dynamic systems in the lumbar spine have been a focal point of interest. However, studies focusing on the thoracic spine are extremely rare ${ }^{(8)}$.

Despite being surrounded by the rib cage, the thoracic spine exhibits considerable range of motion as shown in studies examining the peak points of flexion and extension of the spine. Bible et al.(9) noted that although the range of motion in the thoracic region was less compared to the cervical and lumbar regions, it played a crucial role in spinal alignment ${ }^{(9)}$.

The total kyphosis angle (T1-L1) in the thoracic spine was $40.2 \pm 11.4$ in flexion and $8.5 \pm 12.8$ in extension ${ }^{(8)}$, and this difference is particularly striking for moving thoracic vertebrae. Morita et al. ${ }^{(8)}$ showed that the segmental kyphosis angle increased during flexion from $\mathrm{T} 1$ to $\mathrm{T} 6-7$ and from $\mathrm{T} 10$ downwards.

Upon examining previous cases treated at our clinic, we found that a majority of surgeries were performed to treat pathologies and protect movement at these levels. The increase in the segmental kyphosis angle observed in these regions during flexion suggests that, similar to the lumbar region, efforts should be made to protect the range of motion. Although it is logical that rigid systems should be used in patients with obvious instability, such as those observed at every level of the spine, dynamic systems can be considered in cases where minimal level of support is sufficient, even if it is in the thoracic region.

Previous cadaver and canine model studies have examined the stability of the thoracic region as well as impairment of this stability upon bone resection. Furthermore, it was also investigated whether the thoracic region has significant pathological status in the range of motion in the cases of flexion, extension and lateral bending ${ }^{(10-12)}$.

Studies examining bone resections found that partial discectomy with resection of the rib head resulted in a significant increase in motion, and unilateral resection of the rib head along with removal of the facet joint did not lead to any significant instability. In case of thoracic disc herniations, posterolateral approaches were typically preferred, with rigid stabilization being the treatment of choice in patients requiring excessive bone resection from the lateral side ${ }^{(13)}$. However, dynamic stabilization was considered to be sufficient in the two cases reported here as massive bone resection was not necessary and there was no evidence of distorted costovertebral joints and ligamentous structures, and the follow-up period was seen to remain uneventful.

Currently, there is no defined treatment protocol for patients with significant disc herniation and thoracic discogenic pain after trauma. Discogenic pain in the lumbar spine is usually treated using dynamic stabilization, and this approach may also be reasonably applied to the thoracic region. Our team 
has previously performed dynamic stabilization using PEEK rod and transforaminal microdiscectomy in the T2-3, T3-4, and T4-5 regions, and the patients typically exhibited rapid, significant improvement in their pain scores and uneventful follow-up periods.

This case report had several limitations. Firstly, the sample size was small, and longer follow-up of a larger number of cases would provide more reliable results. Secondly, the small sample size also made statistical evaluation of the results difficult. Thirdly, development of an optimal system was not possible. The PEEK rods used in this study were straight $(6 \mathrm{~mm}$ in diameter) and were not specifically designed for use in the thoracic spine, and dynamic systems developed in accordance with the anatomy of the thoracic region (for physiological thoracic kyphosis) may produce better regional range of motion in the thoracic spine. Future studies using similar techniques and a multi-centric approach should be carried out for more generalizable results.

In conclusion, dynamic systems may be considered as a potential surgical treatment option in patients exhibiting thoracic spine pathologies, such as stenosis and disc herniation, without severe bony resection, such as costovertebral joint, pedicle, corpus. However, better evidence from larger studies as well as biomechanical development of industrial dynamic systems is necessary as this is still a very new concept.

\section{Ethics}

Informed Consent: Verbal informed consent was obtained from the patients.

Peer-review: Externally peer-reviewed.

\section{Authorship Contributions}

Surgical and Medical Practices: A.Ö., E.A., O.K., O.Y., M.Y., S.D., Concept: S.D., A.Ö., M.Y., Design: A.Ö., O.K., Data Collection or Processing: A.Ö., E.A., Analysis or Interpretation: E.A., M.Y., Literature Search: O.K., S.D., Writing: A.Ö., E.A., O.K.

Conflict of Interest: No conflict of interest was declared by the authors.
Financial Disclosure: The authors declared that this study received no financial support.

\section{REFERENCES}

1. Aizawa T, Kokubun S, Ozawa H, Kusakabe T, Tanaka Y, Hosnikawa T, et al. Increasing incidence of degenerative spinal diseases in Japan during 25 years: the registration system of spinal surgery in Tohoku University spine society. Tohoku J Exp Med. 2016;238:153-63.

2. Duarte RM, Vaccaro AR. Spinal infection: state of the art and management algorithm. Eur Spine J. 2013;22:2787-99.

3. Otani K, Yoshida M, Fujii E, Nakai S, Shibasaki K. Thoracic disc herniation. Surgical treatment in 23 patients. Spine. 1988;13:1262-7.

4. Youdas JW, Carey JR, Garrett TR. Reliability of measurements of cervical spine range of motion-comparison of three methods. Phys Ther. 1991;71:98-104.

5. Youdas JW, Garrett TR, Suman V], Bogard CL, Hallman HO, Carey JR. Normal range of motion of the cervical spine: an initial goniometric study. Phys Ther. 1992;72:770-80.

6. Nattrass CL, Nitschke JE, Disler PB, Chou MJ, Ooi KT. Lumbar spine range of motion as a measure of physical and functional impairment: an investigation of validity. Clin Rehabil. 1999;13:211-8.

7. $\mathrm{Ng} J \mathrm{~K}$, Kippers $\mathrm{V}$, Richardson CA, Parnianpour M. Range of motion and lordosis of the lumbar spine: reliability of measurement and normative values. Spine (Phila Pa 1976). 2001;26:53-60.

8. Morita D, Yukawa Y, Nakashima H, Ito K, Yoshid G, Machino M, et al. Range of motion of thoracic spine in sagittal plane. Eur Spine J. 2014;23:673-8.

9. Bible JE, Biswas D, Miller CP, Whang PG, Grauer JN. Normal functional range of motion of the cervical spine during 15 activities of daily living. Clin Spine Surg. 2010;23:15-21.

10. Takeuchi T, Abumi K, Shono Y, Oda I, Kaneda K. Biomechanical role of the intervertebral disc and costovertebral joint in stability of the thoracic spine: a canine model study. Spine (Phila Pa 1976). 1999;24:1414-20.

11. Liebsch C, Graf N, Appelt K, Wilke HJ. The rib cage stabilizes the human thoracic spine: An in vitro study using stepwise reduction of rib cage structures. PloS one. 2017;12:0178733.

12. Lubelski D, Healy AT, Mageswaran P, Benzel EC, Mroz TE. Biomechanics of the lower thoracic spine after decompression and fusion: a cadaveric analysis. Spine J. 2014;14:2216-23.

13. Oppenlander ME, Clark JC, Kalyvas J, Dickman CA. Indications and techniques for spinal instrumentation in thoracic disk surgery. Clin Spine Surg. 2016;29:E99-106. 